\title{
A two-stage conversion process for AZ31B corrosion
}

\author{
Jie Wang ${ }^{1}$ \\ ${ }^{1}$ Department of Mechanical \& Mechatronics Engineering \\ University of Waterloo \\ Waterloo, Canada \\ j756wang@uwaterloo.ca
}

\author{
Hamid Jahed ${ }^{2}$ \\ ${ }^{2}$ Department of Mechanical \& Mechatronics Engineering \\ University of Waterloo \\ Waterloo, Canada \\ hjahedmotlagh@uwaterloo.ca
}

\author{
Xin Pang ${ }^{3}$ \\ ${ }^{3}$ CanmetMATERIALS \\ Natural Resources Canada \\ Hamilton, Canada \\ xin.pang@canada.ca
}

\begin{abstract}
Permanganate phosphate coating is considered as one of the most promising alternative coatings to chromate conversion coating because of the similarity between permanganate and chromate. However, the permanganate phosphate coating always has net-work cracks. In this paper, a thick and crack-free permanganate phosphate coating was developed by a two-stage conversion process. Results of scanning electron microscope (SEM) with X-ray diffraction (XRD) analysis showed that some more corrosion resistant compounds appeared in the coating after a two-stage conversion treatment, which were not found in the single conversion coating. Moreover, the two-stage conversion coating has a higher thickness with few cracks. Furthermore, electrochemical tests and salt spray test further exhibited that the two-stage conversion coating had a better corrosion performance than either of the two single conversion coatings.
\end{abstract}

Keywords-AZ31; Conversion coating; Two stage process; Corrosion

\section{INTRODUCTION}

Two major obstacles have limited the expansion of Mg alloy use in transportation industry. The limited slip systems at room temperature leads to activation of deformation twinning which causes different yield strengths in tension and compression [1-2] (which is different from hydrostatic stress dependent strength different effect [3] seen in high strength steel). The high corrosion susceptibility of magnesium alloys extremely restricts their further application in automotive, aerospace industries and electronics [4]. Presently, the most widely used method in industries to provide the protection on magnesium and its alloys is generally the chromate conversion coating. However, the inevitable environmental and health problems caused by hexavalent chromate leads to a real necessity of developing alternative conversion coatings. During the past 20 years, a few environmental friendly conversion coatings were proposed to be aimed at replacing chromate conversion coating, including metal phosphate coatings, rare earth coating, stannate coating, etc [5-8].

Compared to chromate conversion coating, permanganate phosphate coatings are more environmental friendly and could provide equivalent corrosion resistance and paint adhesion. In recent years, varieties of research related to phosphate permanganate coating have been made on magnesium alloys. Hawke et al. [9] developed a coating consisting of an agglomerate of well-formed crystals with the coating thickness of 4-6 $\mu \mathrm{m}$ using a conversion bath containing $\mathrm{KMnO}_{4}$ and $\mathrm{NH}_{4} \mathrm{H}_{2} \mathrm{PO}_{4}$, which showed good corrosion resistance and paint base performance. Typically, permanganate phosphate coatings have severe cracks, through which corrosive spices could readily reach the Mg substrate. Jian, etc. [10] reported that a phosphate-permanganate conversion coating without cracks was able to be fabricated in a strongly acidic solution which exhibited excellent corrosion resistance. However, this coating is too thin and too weak. To date, there are no work on magnesium alloys reporting a permanganate phosphate conversion coating that is both thick and crack-free.

In the present study, a two-stage conversion process is proposed to form a dense and thick phosphate-permanganate coating. The microstructure and corrosion resistance of this two-stage conversion coating was evaluated by SEM-EDS, electrochemical testing. Results showed that this two-stage conversion coating were both dense and thick that the corrosion resistance was improved compared to the single-step conversion coating. 


\section{MATERIALS AND EXPERIMENTS}

\section{A. Materials and surface preparation}

Specimens of AZ31B [11-12] cast alloy with a size of $3 \times 25.4 \times 50.8 \mathrm{~mm}$ taken from a cylindrical ingot were utilized as the test material. These coupons were mechanically grinded to $1200 \#$ using emery paper, ultrasonic degreased in acetone, washed in ethanol and dried in air stream.

\section{B. Conversion coating treatment and characterization methods}

Potassium permanganate (15g/L KMnO4), potassium dihydrogen phosphate (3g/L KH2PO4), manganese sulfate $(4 \mathrm{~g} / \mathrm{L} \mathrm{MnSO} 4)$ and ethylenediaminetetraacetic acid, namely EDTA (1g/L C10H16N2O8) were used to prepare the aqueous conversion bath. The two-stage conversion process was firstly conducted in a low $\mathrm{pH}$ bath and then was immediately treated by a high $\mathrm{pH}$ solution Another two single stage coatings were also separately obtained as a comparison by a single low $\mathrm{pH}$ solution treatment (marked as LP treatment) and a single high $\mathrm{pH}$ solution treatment (marked as HP treatment).

The surface morphology, microstructure and chemical composition of the conversion coating were characterized using scanning electron microscopy (SEM) and energy-dispersive spectrometry (EDS). The potentiodynamic polarization and electrochemical impedance spectroscopy (EIS) measurements were performed in $3.5 \%$ sodium chloride $(\mathrm{NaCl})$ using a potentiostat/galvanostat electrochemical system (Solartron SI 1287 and 1255B). Prior to the polarization scan and EIS measurement, each sample was immersed in the testing solution for $30 \mathrm{~min}$ to reach a steady open circuit potential (OCP). The potentiodynamic polarization measurement was conducted by sweeping the potential from $-100 \mathrm{mV}$ to $+500 \mathrm{mV}$ vs the OCP at a scan rate of $1 \mathrm{mV} / \mathrm{s}$. For EIS analysis, each spectrum was recorded at the OCP in frequencies ranging from $100 \mathrm{kHz}$ to $10 \mathrm{mHz}$, with a sinusoidal signal amplitude of $10 \mathrm{mV}$. All experimental data were presented in the form of the average \pm the standard deviation of three measurements.

The salt spray chamber test was performed according to the SAE J2334 standard. In this test, the coupons were placed at an angle of $15^{\circ}-30^{\circ}$ from the vertical direction in a chamber. One 24-hour cycle includes a 6 hours exposure in $100 \%$ condensing humidity at around $50^{\circ} \mathrm{C}$, a 15 minutes exposure at $25^{\circ} \mathrm{C}$ to a fog containing 0.5 wt. $\% \mathrm{NaCl}, 0.1 \% \mathrm{CaCl} 2,0.075 \% \mathrm{NaHCO} 3$ and a 17.75 hours exposure in a dry environment at $60^{\circ} \mathrm{C}(50 \%$ relative humidity).

\section{RESULTS AND DISCUSSION}

\section{A. Surface morphology and coating composition analysis}

Figure 1.1 shows the surface morphology of the coating obtained by the two-stage conversion process described above. Another two coatings, i.e. the most corrosion resistant from the low $\mathrm{pH}$ treatment and the most corrosion resistant from the high $\mathrm{pH}$ treatment, are also presented in the figure together with the bare alloy for comparison. In general, all the coatings displayed similar surface morphology with networks of shallow cracks except that some cracks in the two-stage coating was slightly widened. The ESD analysis suggested that the second phase particles in the bare alloy were oxidized after the conversion process, as shown in the Table. And it can be seen from Figure that more oxidized second phase particles were seen in the coating from the high $\mathrm{pH}$ treatment (HP coating) than that from the low $\mathrm{pH}$ bath (LP coating). The fact that the second phase particles can be seen on the coating surface indicates that the coating was quite thin. The most interesting aspect of EDS results is that some manganese oxides were also detected in the two-stage conversion coating, as shown by the spot $\mathrm{D}$ in Figure (d). Manganese oxides $\left(\mathrm{MnO} / \mathrm{MnO}_{2} / \mathrm{Mn}_{2} \mathrm{O}_{3}\right)$ are generally more corrosion resistant than $\mathrm{MgO}$ and $\mathrm{Al}_{2} \mathrm{O}_{3}$. Therefore, this two-stage conversion process has the potential to further improve corrosion resistance of the Mn-P coating, as compared to a single conversion process. Additionally, the thickness of each coating could be evaluated from the weight gain of the coated samples, as presented in Figure . It distinctly demonstrated that the two-stage conversion coating had the highest thickness and the HP coating film was the thinnest, indicating that the two-stage conversion process can be used to grow thick and corrosion resistant $\mathrm{Mn}-\mathrm{P}$ coating on $\mathrm{Mg}$ alloys.
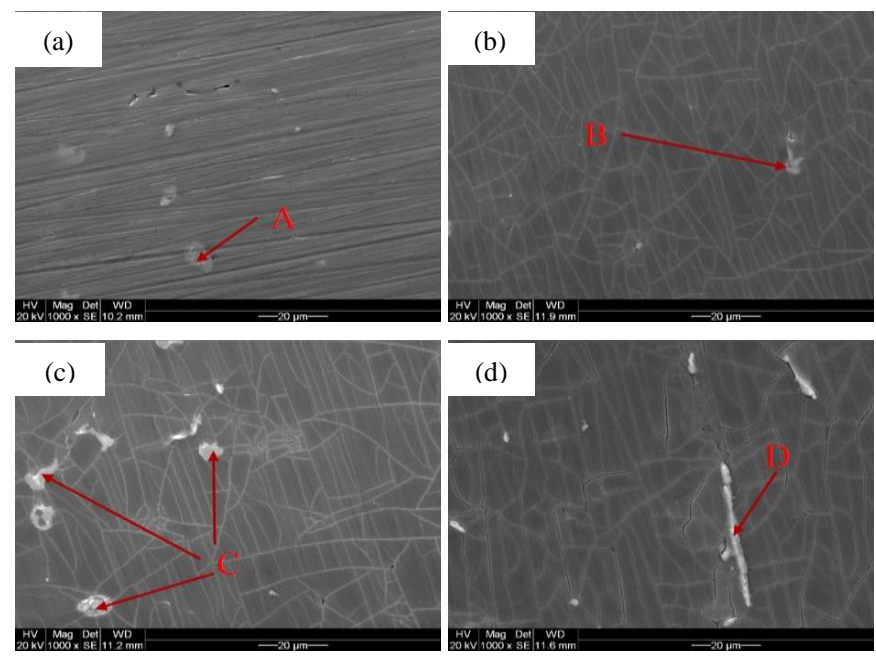

Figure 1.1 The surface morphology of (a) the bare alloy; (b) the coating obtained by low $\mathrm{pH}$ treatment (LP coating); (c) the coating obtained by high $\mathrm{pH}$ treatment (HP coating); (d) Two-stage coating.

Table 1 Chemical composition (atm.\%) of the compounds as indicated in

\begin{tabular}{cccccc}
\multicolumn{6}{c}{ Figure 1.1 } \\
\hline Spot & $\mathrm{Mg}$ & $\mathrm{Al}$ & $\mathrm{Zn}$ & $\mathrm{Mn}$ & $\mathrm{O}$ \\
\hline $\mathrm{A}$ & 90.65 & 6.88 & 2.47 & & \\
$\mathrm{~B}$ & 90.50 & 3.69 & 3.81 & & 2.00 \\
$\mathrm{C}$ & 67.64 & 19.01 & 12.18 & & 1.16 \\
$\mathrm{D}$ & 50.45 & 9.45 & 2.31 & 25.04 & 9.79 \\
\hline
\end{tabular}




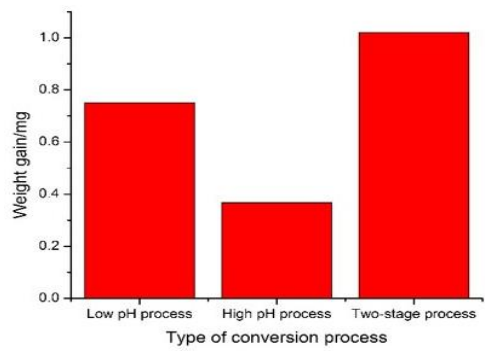

Figure 1.2 Weight gain of the samples after being treated by different conversion process

\section{B. Electrochemical test}

Figure shows the potentiodynamic polarization curves of the various conversion coated $\mathrm{AZ31B}$ in $3.5 \% \mathrm{NaCl}$ solution. Generally, the cathodic polarization curve is related to the evolution of hydrogen and the anodic polarization curve represents the corrosion resistance of the coating. As can be seen in the figure below, both the anodic and cathodic polarization curves of the conversion coatings shifted toward the lower current direction (left) significantly compared to those of the bare alloy, indicating that both the anodic reaction and cathodic reactions were inhibited and hence the corrosion resistance of the AZ31B was effectively improved by the conversion coating. Moreover, it can be observed that a passive region (defined as the potential difference between the corrosion potential $\mathrm{E}_{\text {corr }}$ and the breakdown potential $\mathrm{E}_{\text {break }}$ ) occurred in the anodic polarization branch of the coated samples. Among all coated samples, the HP coating exhibited the largest passive region of $432.2 \mathrm{mV}$. From the polarization test results we can see that the HP coating and two-stage coating showed similar corrosion behavior and both were more corrosion resistant than the LP coating.

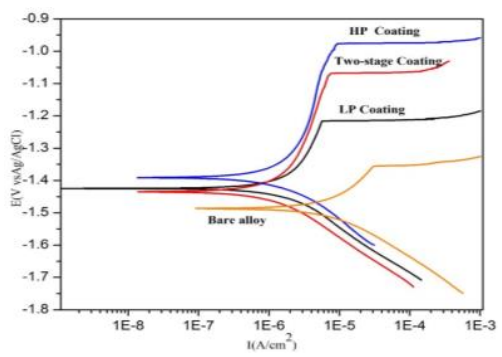

Figure 1.3 Polarization curves of the bare alloy and different conversion coated samples

Electrochemical impedance spectroscopy (EIS) was then used to further study the corrosion resistance of the coated samples. As can be clearly observed from the Bode plots (Figure ) of various conversion coatings and the bare alloy, the two-stage conversion coating exhibited the highest impedance values in the low frequency range. The impedance generally represents the ability of the coating to resist the flow of electrical current. Higher impedance suggests a lower anodic dissolution rate. Therefore, from the point view of EIS results, the two-stage conversion coating shows the highest corrosion resistance.

From the results of the electrochemical tests, it can be concluded that the two-stage conversion process resulted in a thick and dense coating with better corrosion resistance than the coating obtained by a single conversion process (LP coating and HP coating).

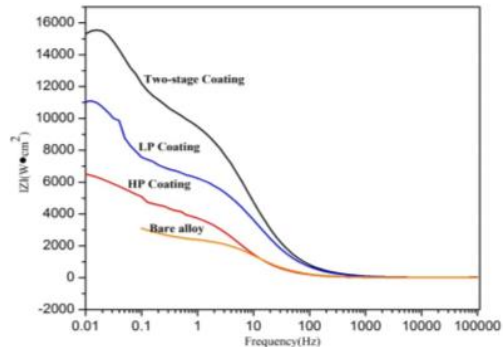

Figure 1.4 Bode plots of the bare alloy and different conversion coated samples

\section{Salt spray test}

To characterize long-term corrosion performances of the coated specimens, salt spray chamber test according to SAE J2334 standard was conducted for up to 168 hours. The edge of the examined samples were all sealed with epoxy to avoid the edge effect in the corrosion process. By visual examination of the conversion coated samples as shown in Figure 1.5, we observed that a few corrosion pits were seen on the surface of LP coated and HP coated samples after a test duration of 96 hours. In contrast, only several small corrosion pits were found on the surface of the two-stage conversion coated specimen. Furthermore, as the testing duration went up to 168 $\mathrm{h}$, corrosion pitting on the LP coated and HP coated coupons became more severe with an increased number of pits. However, the corrosion of two-stage conversion coated coupon did not deteriorate so much with the increasing testing time.
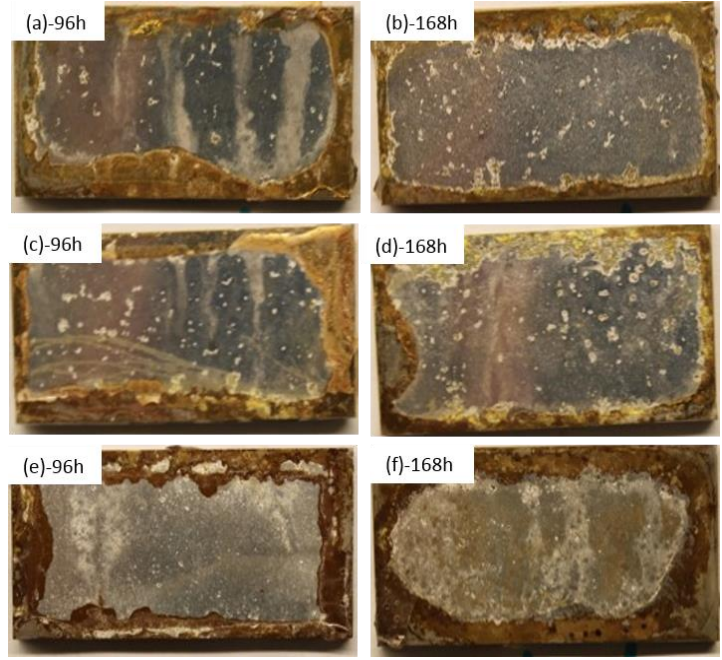

Figure 1.5 Salt spray test results conversion coated samples: (a)(b) LP coating; (c)(d) HP coating; (e)(f) Two-stage coating

\section{CONCLUSIONS}

A two-stage conversion process, namely, the treatment in a low $\mathrm{pH}$ solution followed by an immediate treatment in a high $\mathrm{pH}$ solution, was developed to deposit a thick and dense protective surface coating on $\mathrm{Mg}$ alloy AZ31B. Results of SEM analysis, electrochemical tests and salt spray test exhibited that the two-stage conversion coating had better 
corrosion performance than either of the two single conversion coatings.

\section{REFERENCES}

[1] Roostaei, Ali A., and Hamid Jahed. "Role of loading direction on cyclic behaviour characteristics of AM30 extrusion and its fatigue damage modelling." Materials Science and Engineering: A 670 (2016): 2640.

[2] Jahed, H., and J. Albinmousa. "Multiaxial behaviour of wrought magnesium alloys-A review and suitability of energy-based fatigue life model." Theoretical and Applied Fracture Mechanics 73 (2014): 97-108.

[3] Casey, J., and H. Jahedmotlagh. "The strength-differential effect in plasticity." International journal of solids and structures 20.4 (1984): 377-393.

[4] Atrens, Andrej, et al. "Review of recent developments in the field of magnesium corrosion." Advanced Engineering Materials 17.4 (2015): 400-453.

[5] Gray, JEl, and Ben Luan. "Protective coatings on magnesium and its alloys-a critical review." Journal of alloys and compounds 336.1-2 (2002): 88-113.
[6] Chen, X. B., N. Birbilis, and T. B. Abbott. "Review of corrosion-resistant conversion coatings for magnesium and its alloys." Corrosion 67.3 (2011): 035005-1.

[7] Shaha, S. K., S. B. Dayani, and H. Jahed. "Influence of Cold Spray on the Enhancement of Corrosion Fatigue of the AZ31B Cast $\mathrm{Mg}$ Alloy." TMS Annual Meeting \& Exhibition. Springer, Cham, 2018.

[8] Diab, Mohammad, Xin Pang, and Hamid Jahed. "The effect of pure aluminum cold spray coating on corrosion and corrosion fatigue of magnesium (3\% $\mathrm{Al}-1 \% \mathrm{Zn})$ extrusion." Surface and Coatings Technology 309 (2017): 423-435.

[9] Hawke, David, and D. L. Albright. "A phosphate-permanganate conversion coating for magnesium." Metal Finishing 93.10 (1995): 34-38.

[10] Jian, Shun-Yi, Yu-Ren Chu, and Chao-Sung Lin. "Permanganate conversion coating on AZ31 magnesium alloys with enhanced corrosion resistance." Corrosion Science 93 (2015): 301-309.

[11] Toscano, Dwayne, et al. "Effect of forging on the low cycle fatigue behavior of cast AZ31B alloy." Materials Science and Engineering: A 706 (2017): 342-356.

[12] Behravesh, Seyed Behzad, Hamid Jahed, and Steve Lambert. "Characterization of magnesium spot welds under tensile and cyclic loadings." Materials \& Design 32.10 (2011): 4890-4900. 